Research Article

\title{
A Study on Nash-Collative Differential Game of $N$-Players for Counterterrorism
}

\author{
Mohamed Abd El-Hady Kassem $\mathbb{D}^{1},{ }^{1}$ Abd El-Monem A. Megahed ${ }^{D}$, ${ }^{2}$ \\ and Hebatallah K. Arafat $\mathbb{D}^{2}$ \\ ${ }^{1}$ Department of Mathematics, Faculty of Science, Tanta University, Egypt \\ ${ }^{2}$ Basic Science Department, Faculty of Computers and Informatics, Suez Canal University, Ismailia, Egypt \\ Correspondence should be addressed to Abd El-Monem A. Megahed; a_megahed15@yahoo.com
}

Received 5 June 2021; Accepted 15 July 2021; Published 24 August 2021

Academic Editor: Wasim Ul-Haq

Copyright (c) 2021 Mohamed Abd El-Hady Kassem et al. This is an open access article distributed under the Creative Commons Attribution License, which permits unrestricted use, distribution, and reproduction in any medium, provided the original work is properly cited.

In this work, by using the Nash-collative approach for a differential game problem between $N$-governments and terrorist organizations, we study governments' cooperation and the role of each government for counterterrorism. Furthermore, we discuss the intertemporal strategic interaction of governments and terrorist organizations, where all world governments have to cooperate to fight terrorism. Also, we study the necessary conditions for finding the optimal strategies for each government to fight terrorism; we discuss the existence of the solution of the formulated problem and the stability set of the first kind of the optimal strategies.

\section{Introduction}

It is clear that the world suffers from many serious problems, and the problem of terrorism is one of the most important and serious problems suffered by the local and international communities throughout the ages, especially in recent times. Because of this, countries are controlled, their wealth is plundered, chaos and ignorance spread among peoples, the country's political and religious identities are lost, individuals are destroyed intellectually, they become truly aimless, corruption prevails, and states fall. To face this problem and uproot terrorism from its roots, cooperation must be made between the governments of different countries and the different governments of the same state. This cooperation extends to the members of all societies, coordination occurs between the governments of different countries, and the public good must be upheld over personal interests. Governments have taken security measures to combat terrorism, such as freezing the assets of terrorist organizations and invading their territories to assassinate terrorists. The measures take into account the reactions of terrorists.

The strength of a terrorist organization changes over time, as terrorists are recruited by existing terrorists, and the rate of terrorist recruitment is affected by their actions and the government's antiterrorist actions. The strength of the organization is evaluated by its resources and activities, such as arming, funding, and the expertise of technology.

The government derives its benefits from reducing terrorist resources and activities, in addition to demonstrating that these terrorist organizations are indiscriminate, but they incur costs through fighting terrorism. However, terrorist organizations try to maximize their power in terms of scale and terrorist attacks. Consequently, this study investigates how to help governments fight terrorism.

In this research, we present and study this problem, explain the cooperation of governments with each other, and formulate this problem as a differential game between different governments and terrorist organizations. To clarify 
the cooperation of governments, to find solutions and to derive optimal strategies for combating terrorism, we will provide a Nash-collative approach to infer the necessary conditions for finding the optimal strategies to combat terrorism. Also, we study the existence of the solution, find it, and study its stability.

The global reputation and optimal control of terrorism was discussed by Caulkins et al. [1]. They proved that success in fighting terrorism relies on community opinion, and the efficiency of water and fire strategies were studied by Caulkins et al. [2]. The first approach implementing a fuzzy differential game to guard territory was discussed by Hsia et al. [3, 4]. They considered the problem to guard territory as a differential game with fuzziness in the distance between the evader and the one guarding, and they discussed that the strategy for this problem is fuzzy. A parametric study of a Nash-collative differential game was discussed by Youness et al. [5]. A differential game as a large-scale problem was discussed by Youness et al. [6]. They presented a Nash approach to solve it. Furthermore, they studied Nash and min-max zero-sum approaches to get the optimal strategy of the differential game problem with fuzzy on the minimum of the objective function [7-9]. Nova et al. [10] studied the Stackelberg and Nash approaches of a differential game in addition to the sensitivity analysis. Cross-country strategic connectivity has been introduced to fight terrorism by Roy and Paul [11]. They analyzed the responses of equilibrium (in terms of defense, $R \& D$, and preemption) to a possible terrorist strafe in a two-country framework using a multistep game with incomplete information. A min-max approach of a differential game was discussed to get the optimal solution of the government and the terror organization by Megahed [12-14]. He studied two problems of governments' visions and terrorist organization and proved that governmental activities are important for fighting terrorism and discussed the Stackelberg differential game with E-differentiable function and Econvex set. In [15], Wrzaczek et al. discussed models of differential terror queue games, as terrorist organizations seek to increase the rates of attacks over time, but at the same time, the government is developing its antiterror activities; in [16], Megahed introduced the Stackelberg approach for counterterrorism.

\section{Nash-Collative Differential Game}

Definition 1. A Nash-collative game is a Nash-equilibrium game in which some players make coalitions.

2.1. $N+M$ Differential Games. Consider that we have $N+M$ players; the $N$ players cost

$$
\begin{aligned}
J_{i}\left(u_{1}, u_{2}, \cdots u_{N}, v_{1}, v_{2}, \cdots, v_{M}\right) & =\phi_{i}\left(x\left(t_{f}\right)\right)+\int_{t_{0}}^{t_{f}} e^{-\rho t} I_{i}\left(t, x(t), u_{1},\right. \\
& \left.u_{2}, \cdots u_{N}, v_{1}, v_{2}, \cdots, v_{M}\right) d t, \quad i=1,2, \cdots N,
\end{aligned}
$$

and the $M$ players cost

$$
\begin{aligned}
J_{j}^{\prime}\left(u_{1}, u_{2}, \cdots u_{N}, v_{1}, v_{2}, \cdots, v_{M}\right) \\
=\phi_{i}^{\prime}\left(x\left(t_{f}\right)\right)+\int_{t_{0}}^{t_{f}} e^{-\eta t} I_{j}^{\prime}\left(t, x(t), u_{1},\right. \\
\left.\quad u_{2}, \cdots u_{N}, v_{1}, v_{2}, \cdots, v_{M}\right) d t, \quad j=1,2, \cdots M,
\end{aligned}
$$

subject to

$$
\dot{x}(t)=f\left(x(t), u_{1}, u_{2}, \cdots u_{N}, v_{1}, v_{2}, \cdots, v_{M}\right), x\left(t_{0}\right)=x_{0},
$$

where $x(t) \in R^{n}$ is the state trajectory of the game and $x$ $\left(t_{0}\right)$ is the initial state for all players.

$u_{1}(t) \in R^{s_{1}}, u_{2}(t) \in R^{s_{2}}, \cdots, u_{N}(t) \in R^{s_{N}}$ and $v_{1}(t) \in R^{m_{1}}$, $v_{2}(t) \in R^{m_{2}}, \cdots, v_{M}(t) \in R^{m_{M}}$ denote the control or the decision of $N$ and $M$ players, respectively, which is taken to be a piecewise continuous function of time.

$f:\left[t_{0}, t_{f}\right] \times R^{n} \times R^{m} \times R^{s} \longrightarrow R^{n}, I_{i}:\left[t_{0}, t_{f}\right] \times R^{n} \times R^{m} \times$ $R^{s} \longrightarrow R^{n}, I_{j}:\left[t_{0}, t_{f}\right] \times R^{n} \times R^{m} \times R^{s} \longrightarrow R^{n}$ are $C^{1} ; \phi_{i}\left(x\left(t_{f}\right)\right)$ is the terminal payoff of the player $i, i=1,2, \ldots, N$, and $\phi_{i}^{\prime}\left(x\left(t_{f}\right)\right)$ is terminal payoff of the player $j, j=1,2, \ldots M$; and $I_{i}\left(t, x(t), u_{1}, u_{2}, \cdots u_{N}, v_{1}, v_{2}, \cdots, v_{M}\right)$ is the running payoff of the player $i, i=1,2, \ldots, N$, and $I_{j}^{\prime}\left(t, x(t), u_{1}, u_{2}\right.$, $\left.\cdots u_{N}, v_{1}, v_{2}, \cdots, v_{M}\right)$ is the running payoff of the player $j, j$ $=1,2, \ldots, M$.

Definition 2. The admissible control $v^{*}=\left(v_{1}^{*}, \cdots, v_{M}^{*}\right)$ is said to be a Nash-collative optimal solution if and only if for all admissible $v=\left(v_{1}, v_{2}, \cdots, v_{M}\right)$, we have

$$
\begin{aligned}
& J_{i}\left(u_{1}^{*}, u_{2}^{*}, \cdots, u_{N}^{*}, v_{1}^{*}, v_{2}^{*}, \cdots, v_{M}^{*}\right) \\
& \quad \leq J_{i}\left(u_{1}, u_{2}, \cdots, u_{N}, v_{1}^{*}, v_{2}^{*}, \cdots, v_{M}^{*}\right), \quad i=1,2, \cdots, N, \\
& J_{j}^{\prime}\left(u_{1}^{*}, u_{2}^{*}, \cdots, u_{N}^{*}, v_{1}^{*}, v_{2}^{*}, \cdots, v_{M}^{*}\right) \\
& \quad \leq J_{j}^{\prime}\left(u_{1}^{*}, u_{2}^{*}, \cdots, u_{N}^{*}, v_{1}, v_{2}, \cdots, v_{M}\right), \quad j=1,2, \cdots, M .
\end{aligned}
$$

Definition 3. Pareto optimal solution: let the controls $v^{*}=$ $\left(v_{1}^{*}, v_{2}^{*}, \cdots, v_{M}^{*}\right)$ be admissible. If there exists $w^{\prime} \in R^{M}$, with $w_{j}^{\prime}>0, j=1,2 \cdots, M$, and $\sum_{j=1}^{M} w_{i}^{\prime}=1$ and $w \in R^{N}, w_{i}>0, i=$ $1,2, \cdots, N, \sum_{i=1}^{N} w_{i}=1$ such that for all $v=\left(v_{1}, v_{2}, \cdots, v_{M}\right)$, we have

$$
\begin{aligned}
& \sum_{i=1}^{N} w_{i} J_{i}\left(u_{1}^{*}, u_{2}^{*}, \cdots, u_{N}^{*}, v_{1}^{*}, v_{2}^{*}, \cdots, v_{M}^{*}\right) \\
& \quad \leq \sum_{i=1}^{N} w_{i} J_{i}\left(u_{1}, u_{2}, \cdots, u_{N}, v_{1}^{*}, v_{2}^{*}, \cdots, v_{M}^{*}\right), \\
& \sum_{j=1}^{M} w_{i}^{\prime} J_{j}^{\prime}\left(u_{1}^{*}, u_{2}^{*}, \cdots, u_{N}^{*}, v_{1}^{*}, v_{2}^{*}, \cdots, v_{M}^{*}\right) \\
& \quad \leq \sum_{j=1}^{M} w_{i}^{\prime} J_{j}^{\prime}\left(u_{1}^{*}, u_{2}^{*}, \cdots, u_{N}^{*}, v_{1}, v_{2}, \cdots, v_{M}\right) .
\end{aligned}
$$


From the concept of coalitions, we suppose that $N$ of these players agree to form a coalition and play against the other players outside the coalition. Let $u=\left(u_{1}, u_{2}, \cdots, u_{N}\right) \in R^{s}, s=$ $\sum_{i=1}^{N} s_{i}$ be the composite control for the players in the coalition and $v=\left(v_{1}, v_{2}, \cdots, v_{M}\right) \in R^{m}, m=\sum_{j=1}^{M} m_{j}$ be the composite control outside the coalition. The problem can be formulated as follows: find $\left(u^{*}, v^{*}\right)$ that solves the problems

$$
\min _{u} J\left(u, v^{*}\right)=\Phi\left(x\left(t_{f}\right)\right)+\int_{t_{0}}^{t_{f}} e^{-\rho t} I\left(x(t), u, v^{*}\right) d t,
$$

where

$$
I=\sum_{i=1}^{N} w_{i} I_{i}, \Phi\left(x\left(t_{f}\right)\right)=\sum_{i=1}^{N} w_{i} \Phi_{i}\left(x\left(t_{f}\right)\right), \sum_{i=1}^{N} w_{i}=1, w_{i} \geq 0,
$$

$$
\min _{v} J^{\prime}\left(u^{*}, v\right)=\Phi^{\prime}\left(x\left(t_{f}\right)\right)+\int_{t_{0}}^{t_{f}} e^{-\eta t} I\left(x(t), u^{*}, v\right) d t
$$

subject to

$$
\dot{x}=f\left(x(t), u^{*}, v\right), x\left(t_{0}\right)=x_{0},
$$

where

$$
I^{\prime}=\sum_{j=1}^{M} w_{j}^{\prime} I_{j}^{\prime}, \Phi^{\prime}\left(x\left(t_{f}\right)\right)=\sum_{j=1}^{M} w_{j}^{\prime} \Phi_{j}\left(x\left(t_{f}\right)\right), \quad \sum_{j=1}^{M} w_{j}^{\prime}=1, \quad w_{j}^{\prime} \geq 0 .
$$

Theorem 4. If $\left(x^{*}, u^{*}, v^{*}\right)$ is an open-loop Nash-equilibrium solution for the problems (6), (8), and (9), then there exist continuous costate functions $\lambda(t):\left[t_{0}, t_{f}\right] \longrightarrow R^{n}, q(t):\left[t_{0}, t_{f}\right]$ $\longrightarrow R^{n}$ and the Hamiltonian functions

$$
\begin{gathered}
H\left(x, u, v^{*}, w_{1}, \cdots, w_{N}, \lambda\right)=I\left(x, u, v^{*}\right)+\lambda f\left(x, u, v^{*}\right), \\
H^{\prime}\left(x, u^{*}, v, w_{1}^{\prime}, \cdots, w_{M}^{\prime}, q(t)\right)=I^{\prime}\left(x, u^{*}, v\right)+q(t) f\left(x, u^{*}, v\right),
\end{gathered}
$$

where $u^{*}=\left(u_{1}^{*}, u_{2}^{*}, \cdots, u_{N}^{*}\right)$ and $v^{*}=\left(v_{1}^{*}, v_{2}^{*}, \cdots, v_{M}^{*}\right)$ such that the following relations are satisfied:

$$
\begin{aligned}
\dot{\lambda}(t) & =\rho \lambda-\frac{\partial H\left(x, u *, v, w_{1}, \cdots, w_{N} \lambda\right)}{\partial x}, \\
\lambda\left(t_{f}\right) & =\sum_{i=1}^{N} w_{i} \frac{\partial \phi_{i}\left(x\left(t_{f}\right)\right)}{\partial x}, \\
\dot{q}(t) & =\eta q(t)-\frac{\partial H^{\prime}\left(x, u, v^{*}, w_{1}^{\prime}, \cdots, w_{M}^{\prime}, q(t)\right)}{\partial x}, \\
q\left(t_{f}\right) & =\sum_{j=1}^{M} w_{i}^{\prime} \frac{\partial \phi_{i}^{\prime}\left(x\left(t_{f}\right)\right)}{\partial x},
\end{aligned}
$$

$$
\begin{gathered}
H\left(x, u^{*}, v^{*}, w_{1}, \cdots, w_{N}, \lambda\right) \leq H\left(x, u, v^{*}, w_{1}, \cdots, w_{N}, \lambda\right), \\
H^{\prime}\left(x, u^{*}, v^{*}, w_{1}^{\prime}, \cdots, w_{M}^{\prime}, q(t)\right) \leq H^{\prime}\left(x, u^{*}, v, w_{1}^{\prime}, \cdots, w_{M}^{\prime}, q(t)\right) .
\end{gathered}
$$

For the proof, see [7].

\section{Stability}

The problem is stable if it is persistent with regard to the data; that is, the problem is stable if when we change the problem "a little," the solution changes only a little.

3.1. Stability with respect to the Parameters $w$ and $w^{\prime}$. We study the stability of the problem with respect to the weights $w$ and $w^{\prime}$ for the Nash-collative differential game to show the role of each player in the coalition.

Definition 5. The stability Nash-collative differential game is denoted by

$$
B\left(w, w^{\prime}\right)=\left\{\Lambda: \Lambda=\left(w, w^{\prime}\right) \in R^{N+M}\right\}
$$

such that the solution of the problem exists, where $w$ $=\left(w_{1}, w_{2}, \cdots, w_{N}\right), \sum_{i=1}^{N} w_{i}=1$, and $w^{\prime}=\left(w_{1}^{\prime}, \cdots, w_{M}^{\prime}\right), \sum_{i=1}^{M}$ $w_{j}^{\prime}=1$.

Definition 6. Suppose that $\left(w, w^{\prime}\right) \in B\left(w, w^{\prime}\right)$ with the corresponding the Nash-collative differential game; the stability set of the first kind for the Nash-collative differential game is defined by

$$
\begin{gathered}
S(u *, v *)=\left\{\Lambda=\left(w, w^{\prime}\right) \in R^{N+M} \mid(u *, v *)\right. \\
\text { is a solution of the problems }(6),(7),(8)\} .
\end{gathered}
$$

Lemma 7. If the cost functionals $J_{i}(u, v, w)$ and $J_{j}^{\prime}\left(u, v, w^{\prime}\right)$

$$
\begin{gathered}
J(u, v, w)=\sum_{i=1}^{N} w_{i} J_{i}\left(u_{1}, \cdots, u_{N}, v_{1}, \cdots, v_{M}\right), \\
J^{\prime}\left(u, v, w^{\prime}\right)=\sum_{j=1}^{M} w_{j}^{\prime} J_{j}^{\prime}\left(u_{1}, \cdots, u_{N}, v_{1}, \cdots, v_{M}\right),
\end{gathered}
$$

are linear with respect to $w_{i}$ and $w_{\imath}^{\prime}$ respectively, then $S\left(u^{*}, v^{*}\right)$ is convex.

Proof. Suppose that $\Lambda_{1}=\left(w_{1}, w_{1}^{\prime}\right), \Lambda_{2}=\left(w_{2}, w_{2}^{\prime}\right) \in S$, then

$$
\begin{gathered}
J\left(u^{*}, v^{*}, w_{1}\right) \leq J\left(u, v^{*}, w_{1}\right), \\
J^{\prime}\left(u^{*}, v^{*}, w_{1}^{\prime}\right) \leq J^{\prime}\left(u, v^{*}, w_{1}^{\prime}\right),
\end{gathered}
$$




$$
\begin{gathered}
J\left(u^{*}, v^{*}, w_{2}\right) \leq J\left(u, v^{*}, w_{2}\right), \\
J^{\prime}\left(u^{*}, v^{*}, w_{2}^{\prime}\right) \leq J^{\prime}\left(u, v^{*}, w_{2}^{\prime}\right) .
\end{gathered}
$$

By multiplying both sides of the above inequalities by $\alpha$ and $(1-\alpha)$, respectively, and adding them, then

$$
\begin{gathered}
J\left(u^{*}, v^{*}, \alpha w_{1}+(1-\alpha) w_{2}\right) \leq J\left(u, v^{*}, \alpha w_{1}+(1-\alpha) w_{2}\right), \\
J^{\prime}\left(u^{*}, v^{*}, \alpha w_{1}^{\prime}+(1-\alpha) w_{2}^{\prime}\right) \leq J^{\prime}\left(u, v^{*}, \alpha w_{1}^{\prime}+(1-\alpha) w_{2}^{\prime}\right),
\end{gathered}
$$

then $S\left(u^{*}, v^{*}\right)$ is convex with respect to the weight parameters $w$ and $w^{\prime}$.

Remark 8. If the cost functionals $J(u, v, w), J^{\prime}\left(u, v, w^{\prime}\right)$ are continuous on the weight space $R^{N+M}$, where $0 \leq w \leq 1$ and $0 \leq w^{\prime} \leq 1$, then the stability of the first kind $S\left(u^{*}, v^{*}\right)$ is closed.

\section{Counterterrorism Problem}

In this section, we discuss the governments and terrorist problems and find the optimal strategies for the government to fight terrorism.

4.1. Governments' Problem. Consider the problem of $N$ -governments and one terrorist organization where the cost functional of the government $i, i=1,2, \cdots, N$, is

$\max _{u_{i}} J_{i}=\int_{0}^{\infty} e^{-\rho_{i} t}\left[\gamma_{i} h_{i}\left(u_{i}, v\right)-c_{i} x_{i}(t)-k v(t)-\alpha_{i} u_{i}(t)\right] d t, \quad i=1,2, \cdots, N$,

and the cost functional of the terrorist organization is

$$
\max _{v} J_{0}=\int_{0}^{\infty} e^{-\rho t}\left[\sigma_{i} x_{i}(t)+\beta v\right] d t
$$

subject to

$$
\dot{x}_{i}=r_{i} x_{i}(t)-h_{i}\left(u_{i}(t), v(t)\right),
$$

where $x(t)$ is the state trajectory of the game which is the stock of the terrorist organization which includes the financial capital, network supporters, and weapons. $u$ is the strategy of the governments, $v$ is strategy of the terrorist organization, $h(u, v)$ is the interaction between the government and the terrorist organization (harvest function), and $\rho$ is the positive decreasing rate of the running payoff. Since the governments are cooperative, then there exist $w_{i} \in R^{s}$, $w_{i} \geq 0, \sum_{i=1}^{N} w_{i}=1$

$$
J=\sum_{i=1}^{N} w_{i} J_{i}=\int_{0}^{\infty} \sum_{i=1}^{N} e^{-\rho_{i} t} w_{i}\left[\gamma_{i} h_{i}\left(u_{i}, v\right)-c_{i} x_{i}(t)-k v(t)-\alpha_{i} u_{i}(t)\right],
$$

$$
\dot{x}_{i}=r_{i} x_{i}(t)-h_{i}\left(u_{i}, v\right),
$$

suppose that the decreasing rate $\left(\rho_{i}\right)$ are the same for all governments.

Then, the Hamiltonian function of the Nash-collative problem

$$
\begin{aligned}
H= & \sum_{i=1}^{N} w_{i} \gamma_{i} h_{i}\left(u_{i}, v\right)-\sum_{i=1}^{N} w_{i} c_{i} x_{i}(t)-k v(t)-\sum_{i=1}^{N} \alpha_{i} w_{i} u_{i} \\
& +\lambda_{i}\left(r_{i} x_{i}-h_{i}\left(u_{i}(t), v(t)\right)\right) .
\end{aligned}
$$

Since in counterterrorism, the governments have to maximize the Hamiltonian, we obtain the necessary conditions

$\frac{\partial H}{\partial u_{i}}=\left(w_{i} \gamma_{i}-\lambda_{i}\right) \frac{\partial h_{i}\left(u_{i}, v\right)}{\partial u_{i}}-\alpha_{i} w_{i}=0 \Rightarrow u_{i}^{*}=u_{i}^{*}\left(w_{i}, \lambda_{i}, \alpha_{i}, v\right)$.

Consider the harvest function $h_{i}\left(u_{i}, v\right)=u_{i}^{\delta} v^{\varepsilon}, 0<\delta<$ $\varepsilon<1$

$\frac{\partial h_{i}}{\partial u_{i}}=\delta u_{i}^{\delta-1} v^{\varepsilon} \Rightarrow u_{i}=\left[\frac{\alpha_{i} w_{i}}{w_{i} \gamma_{i} \delta-\delta \lambda_{i}}\right]^{1 /(\delta-1)} v^{-\varepsilon /(\delta-1)}$

In (28), when terrorist organizations become active, governments double their activities in order to root out terrorism; this is evident in Figure 1.

The costate variable has to follow the differential equation

$$
\dot{\lambda}_{i}=\rho \lambda_{i}-\frac{\partial H}{\partial x_{i}}=\left(\rho+r_{i}\right) \lambda_{i}-w_{i} c_{i}
$$

With the optimal control $u_{i}^{*}(v)$, the harvest function is

$$
h\left(u_{i}, v\right)=\left[\frac{\alpha_{i} w_{i}}{w_{i} \gamma_{i} \delta-\delta \lambda_{i}}\right]^{\delta /(\delta-1)} v^{-\varepsilon /(\delta-1)}
$$

4.2. The Terrorist Organization Problem. Consider the payoff functional of the terrorist organization

$$
\max _{v} J_{0}=\int_{0}^{\infty} e^{-\rho t}\left[\sigma_{i} x_{i} t+\beta v\right] d t
$$

and the state trajectory

$$
\dot{x}_{i}=r_{i} x_{i}(t)-h_{i}\left(u_{i}(t), v(t)\right) \text {. }
$$

The Hamiltonian function of the terrorism

$$
H_{0}=\sigma_{i} x_{i}(t)+\beta v+\eta_{i}\left(r_{i} x_{i}-h_{i}\left(u_{i}, v\right)\right)
$$

As the optimal control of the terrorists have to maximize the Hamiltonian function 


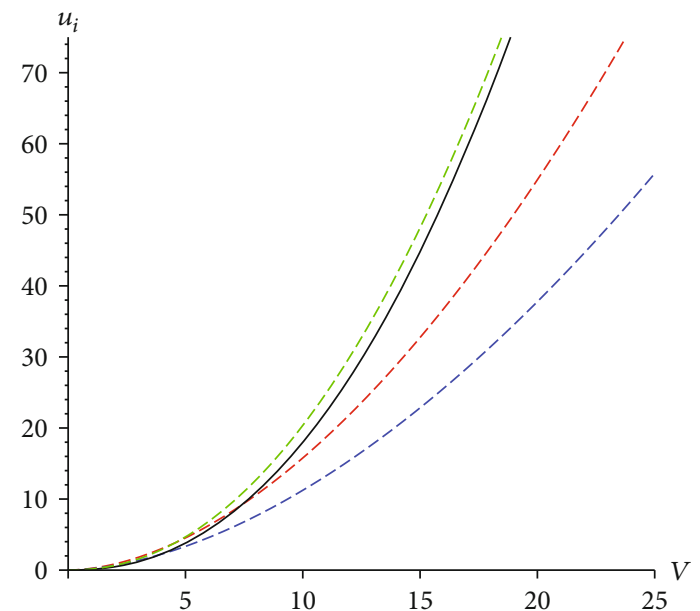

FIGURE 1: The relation between the strategies of governments $u_{i}$ and the strategy of terrorism $v$.

$$
\frac{\partial H_{0}}{\partial v}=\beta-\eta_{i} \frac{\partial h_{i}\left(u_{i}, v\right)}{\partial v}=0 \Rightarrow v^{*}=v^{*}\left(u_{i}\right)
$$

The costate variable for the terrorist problem

$$
\dot{\eta}_{i}=\mu \eta_{i}-\frac{\partial H_{0}}{\partial x_{i}}=\left(\mu-r_{i}\right) \eta_{i}-\sigma_{i}
$$

4.3. Existence. Now, we discuss the existence of the solution for the following system of differential equation; then, we have to integrate equations (36), (37), and (38) on the interval $[0, t]$,

$$
\begin{aligned}
& \dot{x}_{i}=r_{i} x_{i}(t)-h_{i}\left(u_{i}, v\right), \\
& \dot{\lambda}_{i}=\left(\rho+r_{i}\right) \lambda_{i}-w_{i} c_{i}, \\
& \dot{\eta}_{i}=\left(\mu-r_{i}\right) \eta_{i}-\sigma_{i},
\end{aligned}
$$

with the initial conditions $x(0)=x_{0}, \lambda_{i}(0)=0$, and $\eta_{i}($ $0)=0$, then

$$
\begin{aligned}
& x_{i}=x_{0}+\int_{0}^{t}\left(r_{i} x_{i}(t)-h_{i}\left(u_{i}, v\right)\right) d t \\
& \lambda_{i}=\int_{0}^{t}\left(\rho+r_{i}\right) \lambda_{i} d t-w_{i} c_{i} t \\
& \eta_{i}=\int_{0}^{t}\left(\mu-r_{i}\right) \eta_{i} d t-\sigma_{i} t
\end{aligned}
$$

By differentiating the equations (39), (40), and (41), we get

$$
\begin{aligned}
& \dot{x}_{i}=r_{i} x_{i}(t)-h_{i}\left(u_{i}, v\right), \\
& \dot{\lambda}_{i}=\left(\rho+r_{i}\right) \lambda_{i}-w_{i} c_{i}, \\
& \dot{\eta}_{i}=\left(\mu-r_{i}\right) \eta_{i}-\sigma_{i},
\end{aligned}
$$

putting $t=0$ in the equations (39), (40), and (41); we get $x(0)=x_{0}, \lambda_{i}(0)=0$, and $\eta_{i}(0)=0$, then the solution exists.

Proposition 9. The optimal control of the differential game problems (6), (9), and (8) with the initial conditions $x_{i}(0)=$ $x_{0}, \lambda_{i}(0)=0$, and $\eta_{i}(0)=0$ are

$$
\begin{aligned}
& u_{i}=\left(\frac{\alpha_{i} w_{i}}{w_{i} \gamma_{i} \delta-\lambda_{i} \delta}\right)^{(\varepsilon-1) /(1-\delta-\varepsilon)}\left(\frac{\beta}{\varepsilon \eta_{i}}\right)^{\varepsilon /(\varepsilon+\delta-1)}, \\
& v=\left(\frac{\beta}{\varepsilon \eta_{i}}\right)^{(\delta-1) /(1-\varepsilon-\delta)}\left(\frac{\alpha_{i} w_{i}}{w_{i} \gamma_{i} \delta-\delta \lambda_{i}}\right)^{\delta /(1-\varepsilon-\delta)},
\end{aligned}
$$

and the harvest function

$$
h_{i}\left(u_{i}^{*}, v^{*}\right)=\left(\frac{\alpha_{i} w_{i}}{w_{i} \gamma_{i} \delta-\lambda_{i} \delta}\right)^{\delta(2 \varepsilon-1) /(1-\delta-\varepsilon)}\left(\frac{\beta}{\varepsilon \eta_{i}}\right)^{1 /(\varepsilon+\delta-1)}
$$

Proof. According to equations (27) and (28), we have

$$
u_{i}=\left[\frac{\alpha_{i} w_{i}}{w_{i} \gamma_{i} \delta-\delta \lambda_{i}}\right]^{1 /(\delta-1)} v^{-\varepsilon /(\delta-1)}
$$

Also, from (34) and $\partial h(u, v) / \partial v=\varepsilon u_{i}^{\delta} v^{\varepsilon-1}$, we have

$$
v=\left(\frac{\beta}{\varepsilon \eta_{i}}\right)^{1 /(\varepsilon-1)} u_{i}^{-\delta /(\varepsilon-1)}
$$

By solving equations (45) and (46), we get

$$
\begin{aligned}
& u_{i}=\left(\frac{\alpha_{i} w_{i}}{w_{i} \gamma_{i} \delta-\lambda_{i} \delta}\right)^{(\varepsilon-1) /(1-\delta-\varepsilon)}\left(\frac{\beta}{\varepsilon \eta_{i}}\right)^{\varepsilon /(\varepsilon+\delta-1)}, \\
& v=\left(\frac{\beta}{\varepsilon \eta_{i}}\right)^{(\delta-1) /(1-\varepsilon-\delta)}\left(\frac{\alpha_{i} w_{i}}{w_{i} \gamma_{i} \delta-\delta \lambda_{i}}\right)^{\delta /(1-\varepsilon-\delta)},
\end{aligned}
$$

with the harvest function

$$
h_{i}\left(u_{i}^{*}, v^{*}\right)=\left(\frac{\alpha_{i} w_{i}}{w_{i} \gamma_{i} \delta-\lambda_{i} \delta}\right)^{\delta(2 \varepsilon-1) /(1-\delta-\varepsilon)}\left(\frac{\beta}{\varepsilon \eta_{i}}\right)^{1 /(\varepsilon+\delta-1)}
$$

The solution of this problem is stable when the weight parameter $\left(w_{i}\right)$ is greater than $\lambda_{i} / \gamma_{i}$ where $\lambda_{i}$ is the costate vector of the government $i$ and $\gamma_{i}$ is the cost coefficient of the harvest function in the payoff of the government $i$. Also, the role of each government $\left(w_{i}\right)$, to fight terrorism, is greater than $\lambda_{i} / \gamma_{i}$. Thus, the stability set of the first kind for this problem is defined as

$$
S\left(u^{*}, v^{*}\right)=\left\{\Lambda=\left(w_{i} \in R^{N}, w_{i}>\frac{\lambda_{i}}{\gamma_{i}}\right)\right\},
$$


such that

$$
\begin{aligned}
& u_{i}=\left(\frac{\alpha_{i} w_{i}}{w_{i} \gamma_{i} \delta-\lambda_{i} \delta}\right)^{(\varepsilon-1) /(1-\delta-\varepsilon)}\left(\frac{\beta}{\varepsilon \eta_{i}}\right)^{\varepsilon /(\varepsilon+\delta-1)}, \\
& v=\left(\frac{\beta}{\varepsilon \eta_{i}}\right)^{(\delta-1) /(1-\varepsilon-\delta)}\left(\frac{\alpha_{i} w_{i}}{w_{i} \gamma_{i} \delta-\delta \lambda_{i}}\right)^{\delta /(1-\varepsilon-\delta)},
\end{aligned}
$$

is the optimal strategy of the counterterrorism problems (21), (22), and (23).

In (46), when governments play their role to the fullest, the government's strategy reaches stability, and this is evident in the red and black curves, also, when the government gives up its role, the governments change their strategies and take strong measures to combat terrorism; this is evident in Figure 2.

In (47), when the government performs its role, the organizations increase their activities until they stabilize at a certain level, this is evident in the red, black, and blue curves, but when the government gives up its role, the terrorist organization is active at a high level, this is evident in the blue curve; this is evident in Figure 3.

In (48), when governments fulfill its role fully, the harvest function is greatest; this is evident in Figure 4.

Proposition 10. The state trajectory (the source stock of the terrorist) and the costate variables $\lambda_{i}$ and $\eta_{i}$ of governments and terrorists are

$$
\begin{aligned}
& x_{i}(t)=\left(x_{i}(0)-\frac{h_{i}\left(u_{i}, v\right)}{r_{i}}\right) e^{r_{i} t}+\frac{h_{i}\left(u_{i}, v\right)}{r_{i}}, \\
& \lambda_{i}(t)=\frac{w_{i} c_{i}}{\rho+r_{i}}-\frac{w_{i} c_{i}}{\rho+r_{i}} e^{\left(\rho+r_{i}\right) t} \\
& \eta_{i}(t)=\frac{\sigma_{i}}{\mu-r_{i}}-\frac{\sigma_{i}}{\mu-r_{i}} e^{\left(\mu-r_{i}\right) t} .
\end{aligned}
$$

Proof. Since the dynamic system of source stock is

$$
\dot{x}_{i}(t)=r_{i} x_{i}-h\left(u_{i}, v\right)
$$

For the constant strategies and the harvest function, then

$$
x_{i}(t) e^{-r_{i} t}=\frac{h_{i}\left(u_{i}, v\right)}{r_{i}} e^{-r_{i} t}+\text { constant }(c) \text {, }
$$
$r_{i}$ and

since $x_{i}(t) \longrightarrow x_{i}(0)$ as $t \longrightarrow 0$, then $c=x_{i}(0)-h_{i}\left(u_{i}, v\right) /$

$$
x_{i}(t)=\left(x_{i}(0)-\frac{h_{i}\left(u_{i}, v\right)}{r_{i}}\right) e^{r_{i} t}+\frac{h_{i}\left(u_{i}, v\right)}{r_{i}} .
$$

Since the costate variable for the government is

$$
\dot{\lambda}_{i}=\left(\rho+r_{i}\right) \lambda_{i}-w_{i} c_{i}
$$

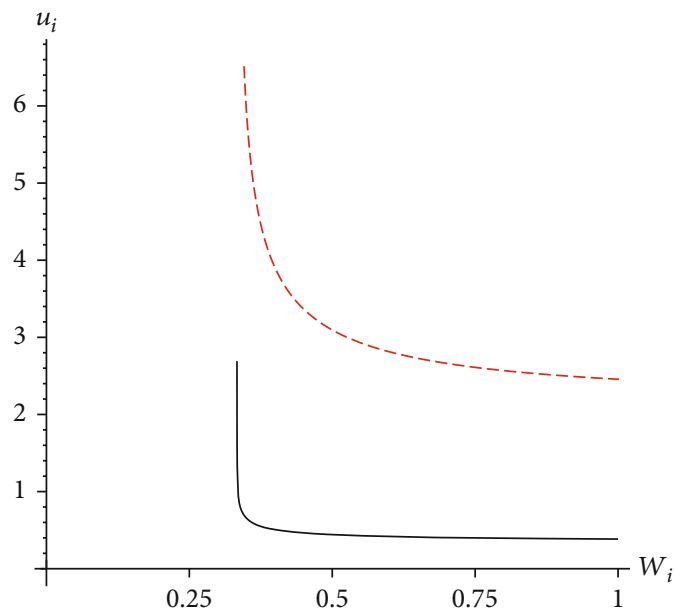

FIGURE 2: The relation between the government's strategies $u_{i}$ and the weight parameter $w_{i}$.

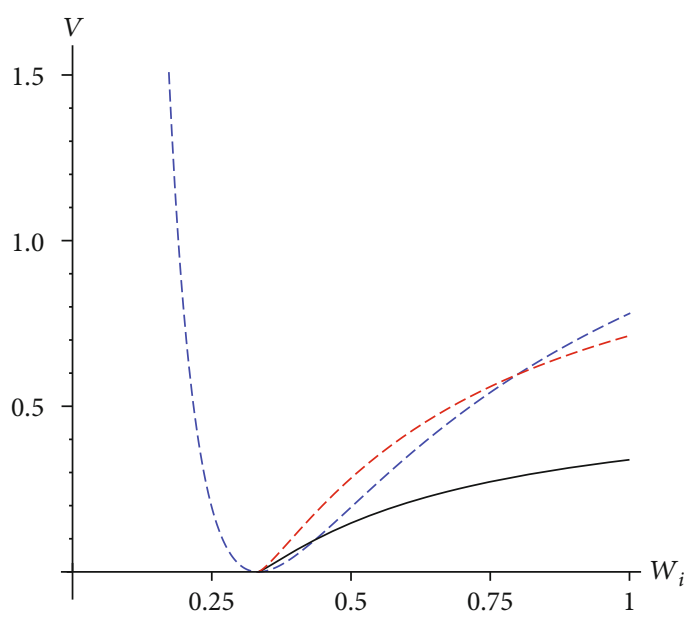

Figure 3: The relation between the strategy of terrorist $v$ and the weight parameter of each government $w_{i}$.

The solution of this differential equation

$$
\lambda_{i} e^{-\left(\rho+r_{i}\right) t}=\frac{w_{i} c_{i}}{\rho+r_{i}} e^{-\left(\rho+r_{i}\right) t}+C(\text { constant })
$$

since $\lambda_{i}(t) \longrightarrow 0$ as $t \longrightarrow 0$, then $C=-\left(w_{i} c_{i} /\left(\rho+r_{i}\right)\right)$ and

$$
\lambda_{i}(t)=\frac{w_{i} c_{i}}{\rho+r_{i}}-\frac{w_{i} c_{i}}{\rho+r_{i}} e^{\left(\rho+r_{i}\right) t}
$$

Also, the costate variable of the terrorist is

$$
\dot{\eta}_{i}=\left(\mu-r_{i}\right) \eta_{i}-\sigma_{i}
$$

Then,

$$
\eta_{i} e^{-\left(\mu-r_{i}\right) t}=+\frac{\sigma}{\mu-r_{i}} e^{-\left(\mu-r_{i}\right) t}+c(\text { constant })
$$




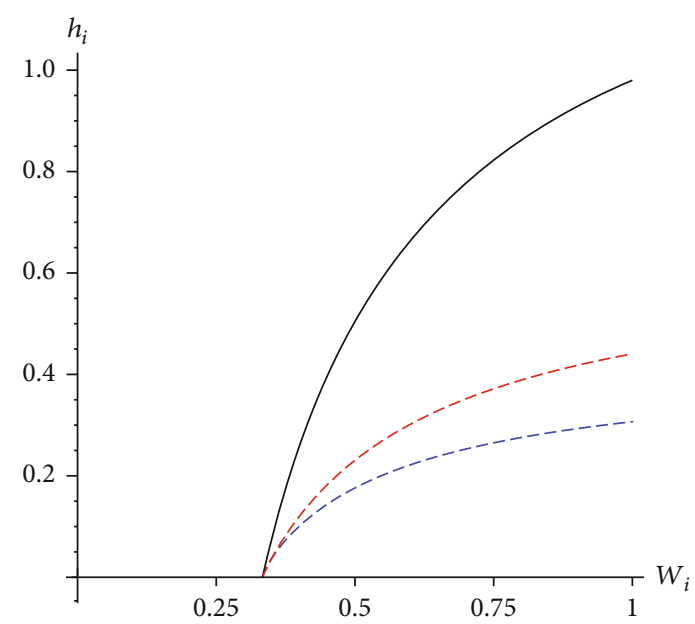

Figure 4: The relation between the harvest function $h\left(u_{i}, v\right)$ and weight parameters $w_{i}$.

since $\eta_{i}(0)=0$, then $c=-\sigma_{i} /\left(\mu-r_{i}\right)$ and

$$
\eta_{i}(t)=\frac{\sigma_{i}}{\mu-r_{i}}-\frac{\sigma_{i}}{\mu-r_{i}} e^{\left(\mu-r_{i}\right) t}
$$

Remark 11. As shown in (54), the resource stock is increasing with time when the initial stock $x_{i}(0)$ is greater than

$$
\frac{1}{r_{i}}\left(\frac{\alpha_{i} w_{i}}{w_{i} \gamma_{i} \delta-\lambda_{i} \delta}\right)^{\delta(2 \varepsilon-1) /(1-\delta-\varepsilon)}\left(\frac{\beta}{\varepsilon \eta_{i}}\right)^{1 /(\varepsilon+\delta-1)} .
$$

Remark 12. The resource stock $x_{i}(t)$ in the duration time [0 $, \infty]$ is

$$
x_{i}(t)=\frac{1}{r_{i}}\left(\frac{\alpha_{i} w_{i}}{w_{i} \gamma_{i} \delta-\lambda_{i} \delta}\right)^{\delta(2 \varepsilon-1) /(1-\delta-\varepsilon)}\left(\frac{\beta}{\varepsilon \eta_{\mathrm{i}}}\right)^{1 /(\varepsilon+\delta-1)} .
$$

The resource stock $x_{i}(t)$ directly decays when the role of each government $w_{i}$ is sufficiently larger.

Lemma 13. For the optimal strategies $u_{i}$ for the Nash-collative, $v$ for the terrorist, and the harvest function $h_{i}\left(u_{i}, v\right)$, the objective values of the cooperative governments $(J)$ and the terrorist $J_{0}$ are

$$
J=\sum_{i=1}^{N} w_{i} J_{i}
$$

$$
\begin{aligned}
J_{i}= & \frac{1}{\rho}\left(\gamma_{i} h_{i}\left(u_{i}, v\right)-k v-\alpha_{i} u_{i}\right)-\frac{c_{i}}{\rho} h_{i}\left(u_{i}, v\right) \\
& -\frac{1}{\rho-r_{i}}\left(x_{i}(0)+\frac{h_{i}\left(u_{i}, v\right)}{r_{i}}\right), \\
J_{0}= & \frac{\sigma_{i}}{\mu-r_{i}}\left(x_{i}(0)-\frac{h_{i}\left(u_{i}, v\right)}{r_{i}}\right)+\frac{\sigma_{i}}{\mu r_{i}} h\left(u_{i}, v\right)+\frac{\beta}{\mu} v .
\end{aligned}
$$

Proof. Since the objective function of government $i$ is

$$
J_{i}=\int_{0}^{\infty} e^{-\rho_{i} t}\left[\gamma_{i} h_{i}\left(u_{i}, v\right)-c_{i} x_{i}(t)-k v(t)-\alpha_{i} u_{i}(t)\right] d t, \quad i=1,2, \cdots, N,
$$

and the state rejector is

$$
x_{i}(t)=\left(x_{i}(0)-\frac{h_{i}\left(u_{i}, v\right)}{r_{i}}\right) e^{r_{i} t}+\frac{h_{i}\left(u_{i}, v\right)}{r_{i}} .
$$
have

By substituting from (66) in (65) and integrating it, we

$$
\begin{aligned}
J_{i}= & \frac{1}{\rho}\left(\gamma_{i} h_{i}\left(u_{i}, v\right)-k v-\alpha_{i} u_{i}\right)-\frac{c_{i}}{\rho} h_{i}\left(u_{i}, v\right) \\
& -\frac{1}{\rho-r_{i}}\left(x_{i}(0)+\frac{h_{i}\left(u_{i}, v\right)}{r_{i}}\right) .
\end{aligned}
$$

Also, by substituting from (66) in (68), we have

$$
J_{0}=\frac{\sigma_{i}}{\mu-r_{i}}\left(\mathrm{x}_{i}(0)-\frac{h_{i}\left(u_{i}, v\right)}{r_{i}}\right)+\frac{\sigma_{i}}{\mu r_{i}} h\left(u_{i}, v\right)+\frac{\beta}{\mu} v,
$$

where $u_{i}, v$, and $h_{i}\left(u_{i}, v\right)$ are defined in Proposition 9

\section{Conclusions}

In this intervention, the cooperation of governments is studied for fighting terrorism by using the Nash-collative approach; the necessity for finding the optimal strategies is derived and we proved that the solution exists and found it. Also, we showed that the optimal strategies are stable when the weight parameter $\left(w_{i}\right)$ is greater than $\left(\lambda_{i} / \gamma_{i}\right)$. Finally, we derived the objective value of each government and its role $\left(w_{i}\right)$ in counterterrorism, the objective of the terrorist organization, and its stock recourse.

\section{Data Availability}

All data generated or analyzed during this study are included in this article.

\section{Conflicts of Interest}

The authors confirm no competing interests.

\section{Authors' Contributions}

The authors contributed to the draft of the manuscript; they read and approved the final manuscript.

\section{Acknowledgments}

This project was funded by the Academy of Scientific Research and Technology (ASRT), Egypt, Grant No. 6053. 


\section{References}

[1] J. P. Caulkins, G. Feichtinger, D. Grass, and G. Tragler, "Optimal control of terrorism and global reputation: a case study with novel threshold behavior," Operations Research Letters, vol. 37, no. 6, pp. 387-391, 2009.

[2] J. P. Caulkins, G. Feichtinger, D. Grass, and G. Tragler, "Optimizing counterterror operations: should one fight with "fire "or "water"?," Computers \& Operations Research, vol. 35, no. 6, pp. 1855-1874, 2008.

[3] K. H. Hsia and J. G. Hsie, "A first approach to fuzzy differential game problem: guarding a territory," Fuzzy Sets and Systems, vol. 55, no. 2, pp. 157-167, 1993.

[4] I. C. Hung, K. H. Hisa, and L. W. Chen, "Fuzzy differential game of guarding a movable territory," Information Sciences, vol. 91, no. 1-2, pp. 113-131, 1993.

[5] E. Youness, J. B. Hughes, and N. A. El-Kholy, "Parametric Nash coalitive differential games," Mathematical and Computer Modelling, vol. 26, no. 2, pp. 97-105, 1997.

[6] E. Youness and A. E.-M. A. Megahed, "A study on large scale continuous differential games," Bulletin of the Australian Mathematical Society, vol. 94, no. 3, pp. 359-368, 2002.

[7] E. Youness and A. E.-M. A. Megahed, "A study on fuzzy differential game," Le Matematche, vol. VI, pp. 97-107, 2001.

[8] S. Hegazy, A. E.-M. A. Megahed, E. Youness, and A. Elbanna, "Min-max zero-sum two persons fuzzy continuous differential games," International Journal of Applied Mechanics, vol. 21, no. 1, pp. 1-16, 2008.

[9] E.-M. A. Abd and S. H. Megahed, "Min-max zero two persons continuous differential game with fuzzy control," African Journal of Clinical and Experimental Microbiology, vol. 2, no. 2, pp. 86-98, 2013.

[10] A. J. Nova, G. Feichtinger, and G. Leitmann, "A differential game related to terrorism: Nash and Stackelberg strategies," Journal of Optimization Theory and Applications, vol. 144, pp. 533-555, 2010.

[11] A. Roy and J. A. Paul, "Terrorism deterrence in a two country framework: strategic interactions between R\&D, defense and pre-emption," Annals of Operations Research, vol. 211, no. 1, pp. 399-432, 2013.

[12] E.-M. A. Abd and A. Megahed, "A differential game related to terrorism: min-max zero-sum two persons differential game," Neural Computing and Applications, vol. 30, no. 3, pp. 865870, 2018.

[13] A. E.-M. A. Megahed, "The development of a differential game related to terrorism: min-max differential game," Journal of Egyptian Mathematical Socity, vol. 25, pp. 306-312, 2017.

[14] A. E.-M. A. Megahed, "A differential game related to terrorism: Stackelberg differential game of E-differentiable and Econvex function," European Journal of Pure and Applied Mathematics, vol. 12, no. 2, pp. 654-668, 2019.

[15] S. Wrzaczek, E. H. Kaplan, J. P. Caulkins, A. Seidl, and G. Feichtinger, "Differential terror queue games," Dynamic Games and Applications, vol. 7, no. 4, pp. 578-593, 2017.

[16] A. E.-M. A. Megahed, "The Stackelberg differential game for counter-terrorism," Quality \& Quantity, vol. 53, no. 1, pp. 207-220, 2019. 